\title{
A Big Data approach to assess the Influence of Road Pavement Condition on Truck Fleet Fuel Consumption
}

\author{
Federico Perrotta, Tony Parry and Luis Neves \\ Nottingham Transportation Engineering Centre, Faculty of Engineering, University of Nottingham, \\ University Park, Nottingham NG7 2RD, UK
}

\begin{abstract}
In Europe, the road network is the most extensive and valuable infrastructure asset. In England, for example, its value has been estimated at around $£ 344$ billion and every year the government spends approximately $£ 4$ billion on highway maintenance (House of Commons, 2011).

Fuel efficiency depends on a wide range of factors, including vehicle characteristics, road geometry, driving pattern and pavement condition. The latter has been addressed, in the past, by many studies showing that a smoother pavement improves vehicle fuel efficiency. A recent study estimated that road roughness affects around 5\% of fuel consumption (Zaabar \& Chatti, 2010). However, previous studies were based on experiments using few instrumented vehicles, tested under controlled conditions (e.g. steady speed, no gradient etc.) on selected test sections. For this reason, the impact of pavement condition on vehicle fleet fuel economy, under real driving conditions, at network level still remains to be verified.

A $2 \%$ improvement in fuel efficiency would mean that up to about 720 million liters of fuel ( $\sim 1$ billion) could be saved every year in the UK. It means that maintaining roads in better condition could lead to cost savings and reduction of greenhouse gas emissions.

Modern trucks use many sensors, installed as standard, to measure data on a wide range of parameters including fuel consumption. This data is mostly used to inform fleet managers about maintenance and driver training requirements. In the present work, a 'Big Data' approach is used to estimate the impact of road surface conditions on truck fleet fuel economy for many trucks along a motorway in England. Assessing the impact of pavement conditions on fuel consumption at truck fleet and road network level would be useful for road authorities, helping them prioritize maintenance and design decisions.
\end{abstract}

Key Words: Road Pavement Condition, Fuel Economy, Big Data, Road Maintenance Strategy

\section{INTRODUCTION}

One of the most important challenges that the world is facing nowadays is the reduction of greenhouse gas (GHG) emissions. This problem has been highlighted in the road transport industry and by road agencies asking themselves how they can play a role in this. Agency decisions influence design, construction and maintenance of roads, but since European road networks are fairly complete, one major impact of agencies is in reducing the emissions of GHGs through adequate maintenance policies.

In England - as in other countries across Europe the road network is the most extensive and valuable infrastructure asset. Recent estimates assess that in England its value is about $£ 344$ billion and every year the government spends approximately $£ 4$ billion for maintaining highways (House of Commons, 2011).
Although the transport industry is one of the major contributors to the economic growth of a country, recent estimates assessed that a quarter of the total energy consumption in Europe is used in transportation, with more than $80 \%$ of it consumed by road vehicles (Haider et al. 2011). Due to continuous reliance on fuel oil derivatives, road transport is an important cause of energy consumption and GHG emissions.

Fuel economy is an essential part of the life-cycle assessment (LCA) analysis of road pavements but frequently not taken into account due to inadequacy of existing models (Zaabar and Chatti, 2010) and lack of a standard and widely accepted methodology (Santero, Harvey and Horvath 2011). Therefore, it is difficult to conduct a complete and reliable assessment.

Fuel consumption is influenced by vehicle technology, road geometry, weather conditions, vehicle 
speed, and pavement condition among other factors (Beuving et al., 2004; Zaabar and Chatti, 2010; and Haider et al. 2011). Sandberg (1990) and Laganier and Lucas (1990), among others, have concluded that rougher roads lead to higher fuel consumption. In particular the impact of road roughness on fuel consumption has been assessed at approximately 5 $\%$ (Zaabar and Chatti 2010) of the whole vehicle fuel consumption. This means that well designed and well maintained roads can influence road vehicle fuel economy, reducing their impact on the environment.

Looking at the latest available statistics it is possible to see that about 36 billion liters of fuel are used every year by road vehicles circulating in England (Department for Transport, 2015), so road conditions account for around $£ 1$ billion every year (depending on the price of fuel). This is equivalent to $25 \%$ of the total annual investment in road maintenance on highways in England. Maintaining some roads in a better condition could therefore lead to environmental mitigation and overall cost savings.

However, conclusions of previous studies of the impact of road condition on fuel consumption cannot be considered completely exhaustive. In fact previous studies consider just a few vehicles driven on a few selected road segments, in specific road conditions, with specific road geometry. Because of this, the impact of road conditions on vehicle fuel consumption at network level under real driving conditions still remains unclear.

In the era of 'Big Data', large amounts of data are collected every day and this includes for road vehicles. Modern trucks are equipped with a wide range of sensors defined in SAE J1939 (SAE International 2002). These sensors collect data about vehicle performance (fuel consumption, vehicle speed and other factors) and they are usually analyzed to help truck fleet managers in their truck maintenance and driver training decision making processes. At the same time, every year, road agencies collect data on road condition (roughness, skid resistance, texture, and stiffness among other parameters).

The objective of this work is to compare truck fuel consumption and road condition data using a big data approach. This will lead to the definition of more accurate models for the LCA of pavements. Using this approach, almost real time data can be used and any generated model can be progressively updated with time, following improvements in vehicle and road technology. This paper reports some initial results exploring the feasibility of this approach.

\section{AIM \& OBJECTIVES}

The main aim of this study is to investigate the feasibility of using a Big Data approach to assess the impact of road pavement conditions on truck fleet fuel consumption at road network level under real driving conditions.

\section{DATA}

A limitation of previous studies of vehicle fuel consumption and road conditions is that measurements have been taken under carefully controlled conditions, on flat roads, testing only a few vehicles driving on a few selected road segments. For this study data from 43 trucks driving for one year over various segments of the M18 motorway in England are considered. 1970 data points for these articulated trucks equipped with $12,419 \mathrm{cc}$, euro 5 engine, driving on M18 in 2015 at $85( \pm 2.5) \mathrm{km} / \mathrm{h}$ using gear 12 are available. These data were chosen for this initial study from hundreds of thousands of records, to remove the influence of truck type, speed and gear from the analysis.

This and other sensor data are collected daily and analyzed to assist truck fleet managers in decision making about vehicle maintenance and driver training.

Each record contains data recorded at an 'event' during the journey of each truck (license number and tracker ID define the specific truck). At any brake, stop or anomaly in vehicle performance etc., or each 2 minutes $(120 \mathrm{~s})$ or 2 miles $(\sim 3,219 \mathrm{~m})$, an event is generated and a data record taken.

Each vehicle's performance database contains hundreds of gigabytes of data but not every record is stored or is useful for the data analysis. The data accessed during this study are:

- the vehicle profile, identifying the vehicle,

- the tracker ID, reference for the system of sensors installed on the vehicle,

- the geographical position of the truck, given in the British National Grid (latitude and longitude) coordinate system (5 meters GPS precision),

- the distance travelled by the vehicle since the previous event (meters),

- the time spent by the vehicle to travel to the current position from the previous event (seconds),

- the total fuel consumed until the current event is recorded (0.001 litres precision, rounded to 0.1 litres for the purpose of reducing database size),

- the air temperature $\left(0.1^{\circ} \mathrm{C}\right.$ precision $)$,

- the current gear,

- the current engine torque percentage,

- the engine revolutions (revs / $\mathrm{min}$ ).

HAPMS (the Highway Asset Performance Management System) is a database owned by Highways England (the agency) which contains all data collected during annual surveys of the condition of the road network. The database contains historical information about each road of the network, including:

- a road identifier code,

- a direction code, 
- the year of construction,

- the latest date of significant maintenance,

- the construction materials,

- roughness measurements,

- texture measurement,

- skid resistance measurement,

- deflection measurement (not considered in this study).

Each record refers to a 10 meter segment of road. Data are linked to their geographical position by coordinates (in WGS84 coordinate system). Because of the different coordinate systems used in data collection for vehicle performance and road pavement condition, the coordinates of vehicle performance are transformed to the WGS84 coordinate reference system in order to compare the data.

In this initial study only information about road surface condition is taken from HAPMS. This includes measurements of roughness (Longitudinal Profile Variance, LPV, at 3 and 10 meters in $\mathrm{mm}^{2}$ ), texture (sensor-measured texture depth in $\mathrm{mm}$ ), skid resistance (SCRIM Coefficient), and road gradient $(0.1 \%$ resolution $)$. Although previous studies used measurements like IRI (International Roughness Index) and MPD (Mean Profile Depth) as roughness and texture measurements they are similar to the LPV and texture measurements used in this study. Road surface roughness and texture have been shown to have a significant effect on fuel consumption in previous experimental studies (Sandberg, 1990, Laganier and Lucas, 1990, du Plessis, Visser and Curtayne, 1990, Beuving et al., 2004, Zaabar and Chatti, 2010, Haider et al., 2011, Zaabar and Chatti, 2012).

\section{METHOD}

A Big Data approach has been taken in this study. 910,591 events have been recorded and are available in total from trucks driven on M18 in 2015.

In order to limit the variables at this initial stage, the data were filtered for truck model, vehicle speed, engine type, road geometry, etc.

In the analysis reported here the following subset of data was used where the records show:

- records for which the trigger event was the default time or distance (i.e. no other driving event (e.g. harsh braking or cornering) triggered the record),

- an average speed of $85 \mathrm{~km} / \mathrm{h}$,

- the initial and final speed were similar to the average speed (calculated as the travelled distance divided by the travelled time) and do not differ by more than $2.5 \mathrm{~km} / \mathrm{h}$ (this assumption makes sure that the vehicle speed is steady between the two considered events),

- no gear change.
No data about the truck payload is currently available. Applying these filters, all the data at steady speed, for a certain type of vehicle can be separately considered and analyzed.

In this study only data for 3-axle tractor with 3axle trailer articulated trucks at $85 \mathrm{~km} / \mathrm{h}$ using gear 12 , equipped with 12,419 cc euro 5 engines are considered. This has been done in order to avoid the influence of speed, engine performance and vehicle type, and results in 1970 records.

\section{RESULTS}

Comparing the vehicle fuel consumption (as liters per 100 kilometers) and the road condition, a predictive model has been generated. Data about the engine torque percentage (as a substitute for the vehicle payload), the road gradient, LPV at 3 and 10 meters wavelength and texture measurements are considered. First each variable has been related to fuel consumption separately in order to estimate the correlation between each single variable and fuel economy.

$$
\begin{aligned}
& F C=25.46+0.12 T \% \\
& F C=26.15+7.18 \mathrm{~g} \% \\
& F C=28.36+3.14 L P V 03 \\
& F C=28.46+0.53 L P V 10 m \\
& F C=26.17+1.80 t
\end{aligned}
$$

where, $F C=$ predicted fuel consumption $[1 / 100 \mathrm{~km}]$; $T \%=$ engine torque percentage on maximum available $[\%] ; g \%=$ road gradient $[\%] ; L P V 03=$ Longitudinal Profile Variance at $3 \mathrm{~m}$ wavelength $\left[\mathrm{mm}^{2}\right]$; $L P V 10=$ Longitudinal Profile Variance at $10 \mathrm{~m}$ wavelength $\left[\mathrm{mm}^{2}\right] ; t=$ texture depth [mm].

Based on the literature review the payload and the gradient are two of the most influential variables (Beuving et al., 2004). However, as already mentioned, no data about the payload is currently available for this study. Therefore the torque generated by the engine for moving the vehicle (moving a certain payload) is used instead.

The relationship between the fuel consumption and the road gradient is shown in Figure 1.

Including only two variables, $T \%$ and $g \%$ in the model we obtain:

$$
F C=24.34+0.068 T \%+6.65 g \%
$$

Then, performing a backward analysis based on the Aikake Information Criterion (AIC, Aikake, 1973) the profile variance and texture data have been included in the model. Among all the models generated the one that shows the lowest AIC coefficient is: 


$$
F C=19.18+0.066 T \%+6.85 g \%+1.91 L P V 10+2.77 t
$$

The correlation coefficient (r) between the predicted and the measured fuel consumption is 0.54 .
The correlation between the predicted and the measured fuel consumption is shown in Figure 2.

\section{Scatter plot for Road Gradient and Fuel Consumption}

referred to 1970 travels at $85 \mathrm{~km} / \mathrm{h}$ avg speed, for trucks with 3 AXLE + 3 AXLE ARTIC and engine 12419 euro 5 using gear 12

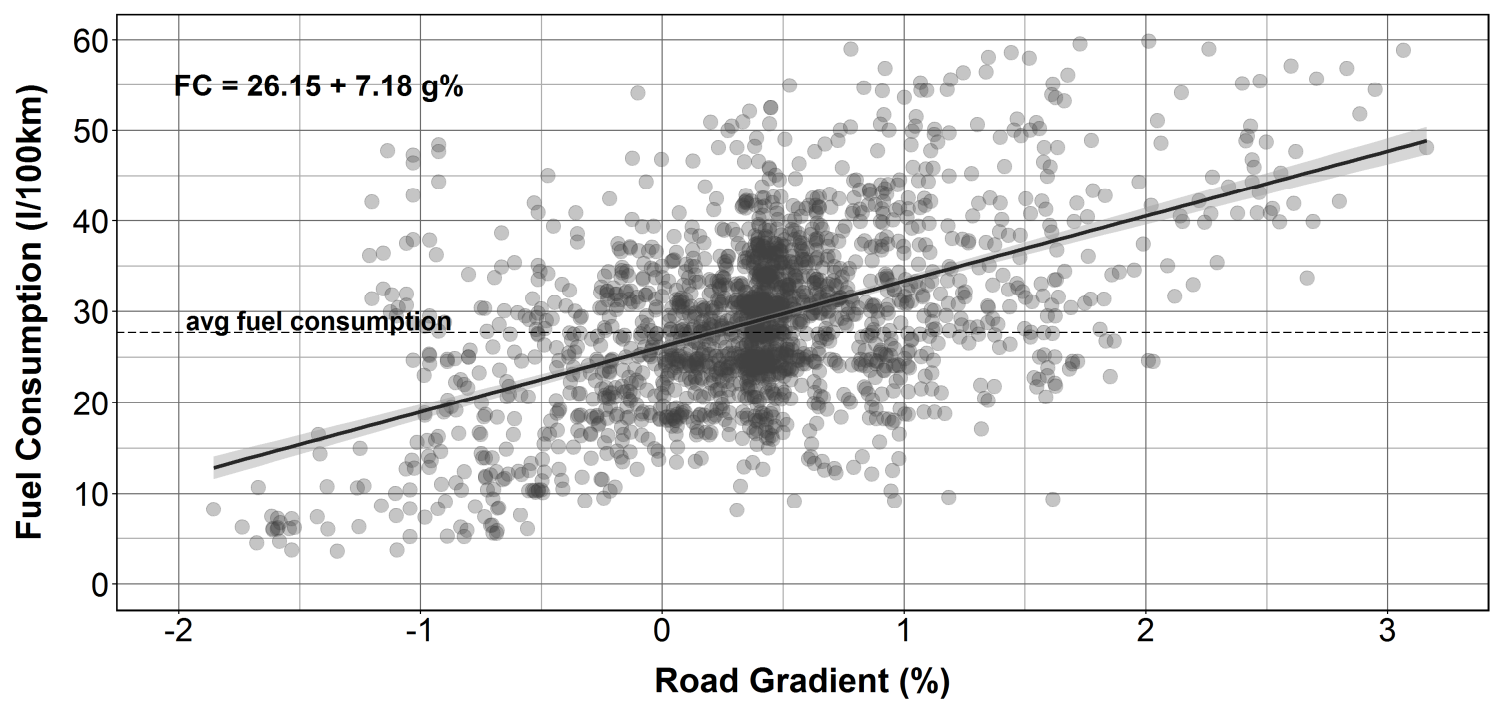

Figure 1- Plot of the direct impact of road gradient [\%] on truck fleet fuel consumption [1/100km] for articulated trucks driven at $85 \mathrm{~km} / \mathrm{h}$ equipped with $12,419 \mathrm{cc}$ euro 5 engine.

\section{Scatter plot for Predicted Fuel Consumption and Real Measurements}

referred to 1970 travels at $85 \mathrm{~km} / \mathrm{h}$ avg speed, for trucks with 3 AXLE + 3 AXLE ARTIC and engine 12419 euro 5 using gear 12

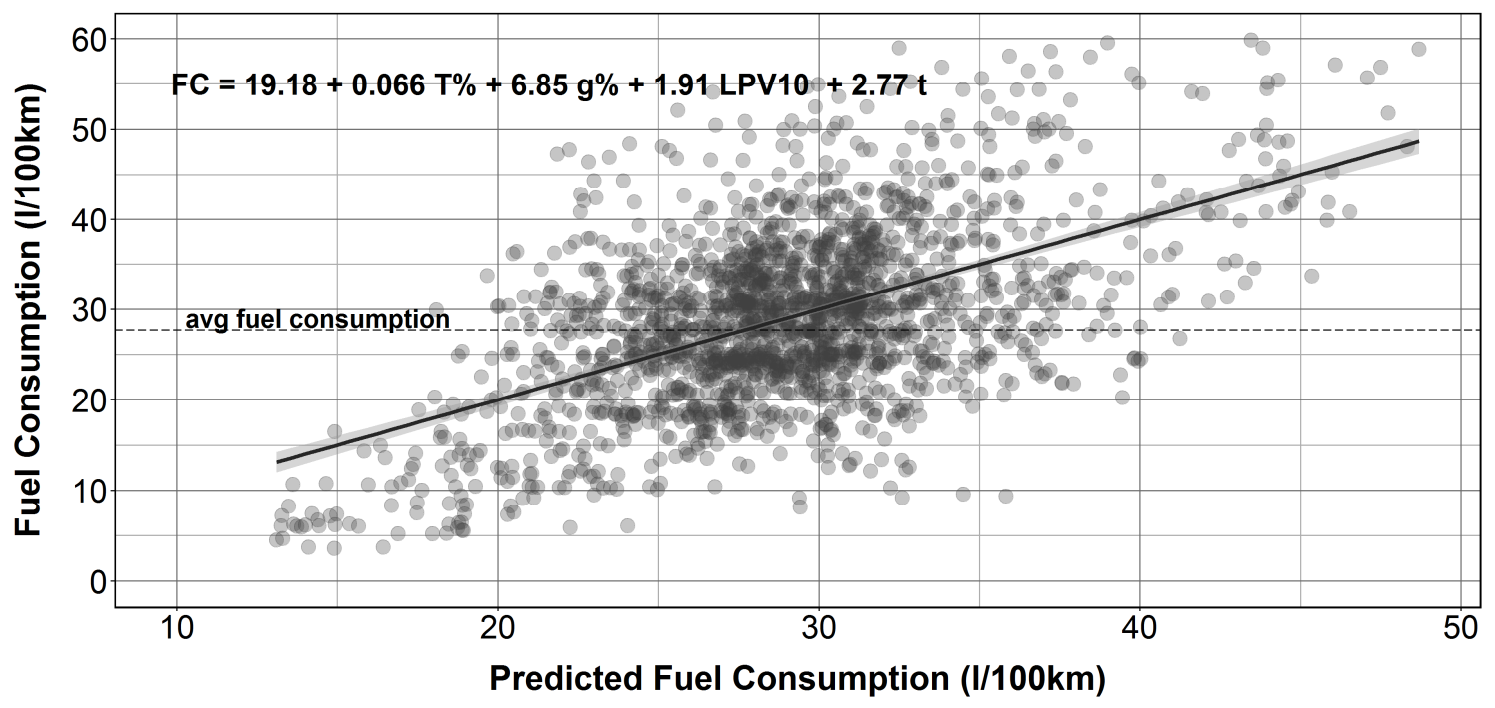

Figure 2 - Plot of the predicted value of fuel consumption [1/100km] with the real measurements for articulated trucks driven at $85 \mathrm{~km} / \mathrm{h}$ equipped with $12,419 \mathrm{cc}$ euro 5 engine.

\section{DISCUSSION}

The generated model considers a limited number of road condition variables (avoiding overfitting) including those ones that previous studies considered to be the most influential on fuel economy. It assesses the impact of road roughness on fuel consumption to be up to $4.1 \%$ and up to $1.25 \%$ for the texture.
Zaabar and Chatti (2010 and 2012) estimated the impact of roughness on fuel consumption at $5 \%$ and our first estimate from this initial work lies slightly below that.

Beuving (2004) reported that for a truck driving at $80 \mathrm{~km} / \mathrm{h}$ the impact of other variables such as the vehicle mass and the gradient of the road is about 40 $\%$ of the entire fuel consumption. The model esti- 
mates that the impact of torque (payload) and gradient measured for this data set is about $41.6 \%$. Compared to experimental studies this gives confidence in this Big Data approach.

Although the results match what was found previously by other authors in experimental studies, they cannot be considered valid as yet. In fact, in this initial study only specific conditions were selected: only one vehicle model was considered, driven at steady speed, $85 \mathrm{~km} / \mathrm{h}$, etc. However, previous studies include many assumptions which may not be valid at network level under real driving conditions. Previous studies in fact considered only few vehicles tested at selected steady speeds on about ten flat road sections. They base their conclusions on a significantly lower amount of data without considering the impact of the considered variables in real driving conditions.

The correlation coefficient between the measured fuel consumption and the predicted value calculated using the generated model is 0.54 . This is a low level of correlation compared to the more controlled experimental studies in the literature but is the result of analyzing 1970 data records for 2 mile long sections over the majority of the $42.6 \mathrm{~km}$ long motorway. Models derived in this way represent real driving conditions (albeit at constant speed and gear in this initial study) for many trucks and over a route length. For these reasons they may be considered more representative of real world fuel consumption than the limited experimental studies. This demonstrates the strength and weakness of the Big Data approach. Although techniques for reducing the noise included in the data exist (and will be implemented soon) the lack of precision in the model estimate is an inevitable consequence of using this approach. Further research using this approach is underway. A better estimate of payload is being developed using a mechanical model based on the engine performance using further sensor data. Also, by considering single trips performed by individual constantly loaded trucks, it might be possible to remove the effect of payload on the fuel consumption estimates. Another potential solution is to identify from position and time data, when and where trucks discharge their loads and consider the fuel consumption of the unladen vehicles for the rest of their journey. It may also be possible to collect data records more frequently and to record the fuel consumption more precisely for a limited number of trucks over a limited time period but this approach will be limited by the size of the generated data set and hence cost. Furthermore, it may be possible to add meteorological data (e.g. wind speed and direction) but because this data is routinely reported only over extended time periods (e.g. average per hour), it may be of limited use.

It is anticipated that including more reliable data using these approaches will improve the generated model, which can then be extended to further types of truck and speeds and a wider road network.

These models of the influence of road condition on fuel consumption can be used to validate those from experimental studies and extend them to truck fleet and road network level. This will allow more confidence in the use of the results in road maintenance decision making, for instance to include vehicle fuel cost and GHG emissions in determining maintenance strategies.

\section{AKNOWLEDGMENTS}

The authors would like to thank Alex Tam (Highways England) for giving permission to use data from the HAPMS database, Mohammad Mesgarpour and Ian Dickinson (Microlise Ltd) for allowing us to use an anonymized part of their truck telematics database and Emma Benbow, David Peeling and Helen Viner (TRL Ltd) for their help in the interpretation of results and for their support in this initial part of the research.

This project has received funding from the European Union Horizon 2020 research and innovation

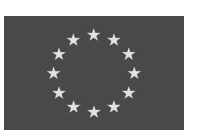
programme under the Marie Sklodowska-Curie grant agreement No. 642453 and it is part of the Training in Reducing Uncertainty in Structural Safety project (TRUSS Innovative Training Network, www.trussitn.eu).

\section{REFERENCES}

Akaike, H. 1973. Information theory and an extension of the maximum likelihood principle. In Second International Symposium on Information Theory, ed. B. N. Petrov and F. Csaki, 267-281. Budapest: Akailseoniai-Kiudo.

Beuving, E., De Jonghe, T., Goos, D., Lindhal, T., and Stawiarski, A., 2004. Environmental Impacts and Fuel Efficiency of Road Pavements. Industry report. Eurobitume \& EAPA BRUSSELS.

Chatti, K. \& Zaabar, I., 2012. Estimating the Effects of Pavement Condition on Vehicle Operating Costs, National Cooperative Highway Research Program, Report 720. Washington, DC.

Du Plessis, H.W., Visser, A.T., and Curtayne P.C. 1990. Fuel Consumption of Vehicles as Affected by Road-Surface Characteristics. ASTM STP 1031 pp. 480-496.

Haider, M., Conter, M., and Glaeser, K.P. 2011. Discussion paper what are rolling resistance and other influencing parameters on energy consumption in road transport, Models for Rolling Resistance in Road Infrastructure Asset Management Systems (MIRIAM), AIT, Austria.

House of Commons, 2011. House of Commons Committee of Public Accounts Departmental Business Planning.

Laganier R. \& Lucas J. 1990. The Influence of Pavement Evenness and Macrotexture on Fuel Consumption. ASTM STP 1031 pp. 454-459, USA 1990. SAE International, 2002. Surface Vehicle Recommended Practice, 4970, pp.724-776. 
SAE International 2002. Vehicle Application Layer - J1939-71 - Surface Vehicle Recommended Practice Rev. Aug. 2002.

Sandberg, Ulf S. I. 1990. Road Macro- and Megatexture Influence on Fuel Consumption. ASTM STP 1031 pp. 460-479.

Santero, N.J., Harvey, J. \& Horvath, A., 2011. Environmental policy for long-life pavements. Transportation Research Part D: Transport and Environment, 16(2), pp. 129-136.

Zaabar, I. \& Chatti, K., 2010. Calibration of HDM-4 models for estimating the effect of pavement roughness on fuel consumption for U. S. conditions. Transportation Research Record, (2155), pp.105-116.

Zaniewski, J.P., 1989. Effect of Pavement Surface Type on Fuel Consumption. Portland Cement Association - Research $\&$ Development Information. Special report. FHWA. 